\title{
The influence of mode of anaesthesia for caesarean delivery on neonatal Apgar scores in the Czech Republic and Slovakia: secondary analysis of the results of an international survey in 2015
}

\author{
Hana Harazima , Petr Stourac ${ }^{b}$, Jan Blahac, Monika Grochova ${ }^{d}$, Radka Klozova ${ }^{e}$, Pavlina Noskovac, Dagmar Seidlova ${ }^{f}$,

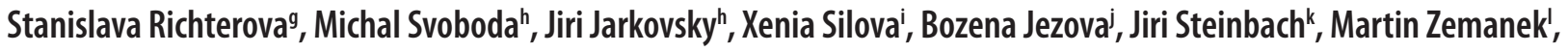 \\ Jitka Mannova ${ }^{\mathrm{m}}$, Jan Slavik ${ }^{\mathrm{n}}$, Zuzana Novakova ${ }^{\circ}$, Lubica Misakova ${ }^{\mathrm{p}}$, Jozef Firment ${ }^{\mathrm{d}}$, OBAAMA-INT Study Group
}

\begin{abstract}
Aims. The purpose of this international survey was to describe the impact of current practices and techniques of caesarean section on the neonatal Apgar score in the Czech Republic (CZE) and Slovakia (SVK).

Methods. All Czech and Slovak departments that provide obstetric anaesthesia were invited to participate in a onemonth (November 2015) prospective study that monitored in details all peripartum anaesthetic practices, delivered by anaesthesiologists. Participating centers recorded all data on-line in the CLADE-IS database (Masaryk University, CZE). Results and Discussions. We collected data of 10119 women who delivered 10226 newborns. A caesarean section was recorded in 25.1\% of deliveries (CZE 23.2\%; SVK 30\%). General anaesthesia was used for caesarean section in 37.5\% of the cases (CZE 40\%, SVK 33\%). There was no statistically significant difference in the Apgar score lower than 7 in the 1, 5 or $10 \mathrm{~min}$ in groups of general and regional anaesthesia for caesarean section, when only elective sections of in-term babies with birth weight over $2500 \mathrm{~g}$ were analyzed. We found no statistically significant differences in the Apgar score in newborns of women intubated for caesarean section in rocuronium $(n=21 ; 2.2 \%)$ and suxamethonium $(n=889 ; 93 \%)$. Conclusion. We found no difference in neonatal outcomes in groups of general and regional anaesthesia for caesarean section when only out-of-risk newborns were analyzed. The risk factors were identified as follows: an acute caesarean section, preterm babies, birth weight less than $2500 \mathrm{~g}$, born in perinatological center and multiple pregnancy - second baby.
\end{abstract}

Trial Registration: ClinicalTrials.gov (ID: NCT02380586) https://clinicaltrials.gov/ct2/show/NCT02380586

Key words: caesarean section, Apgar score, rocuronium, suxamethonium, international survey, general anaesthesia, rapid sequence induction, neonatal outcome

Received: February 18, 2019; Accepted: March 4, 2019; Available online: April 9, 2019

https://doi.org/10.5507/bp.2019.008

${ }^{a}$ Department of Anaesthesiology and Intensive Care Medicine, Faculty of Medicine, Masaryk University and University Hospital Brno, Brno, Czech Republic

${ }^{b}$ Department of Paediatric Anaesthesiology and Intensive Care Medicine, Faculty of Medicine, Masaryk University and University Hospital Brno, Brno, Czech Republic

'Department of Anaesthesiology and Intensive Care Medicine, $1^{\text {st }}$ Faculty of Medicine, Charles University and General University Hospital in Prague, Prague, Czech Republic

${ }^{d}$ Department of Anaesthesiology and Intensive Care Medicine, L. Pasteur University Hospital, Kosice, Slovakia

${ }^{e}$ Department of Anaesthesiology and Intensive Care Medicine, $2^{\text {nd }}$ Faculty of Medicine, Charles University and Motol University Hospital, Prague, Czech Republic

${ }^{f} 2^{n d}$ Department of Anaesthesiology and Resuscitation, Faculty of Medicine, Masaryk University and University Hospital Brno, Brno, Czech Republic

${ }^{9}$ Department of Anaesthesiology and Intensive Care Medicine, University Hospital Martin, Martin, Slovakia

'Institute of Biostatistics and Analyses, Faculty of Medicine, Masaryk University, Brno, Czech Republic

'Department of Anaesthesiology and Intensive Care Medicine, Faculty of Medicine in Hradec Kralove, Charles University and University Hospital Hradec Kralove, Hradec Kralove, Czech Republic

'Department of Anaesthesiology and Intensive Care Medicine, Opava Hospital, Opava, Czech Republic

${ }^{k}$ Department of Anaesthesiology and Intensive Care Medicine, Horovice Hospital, Horovice, Czech Republic

'Department of Anaesthesiology and Intensive Care Medicine, Chrudim Hospital, Chrudim, Czech Republic

${ }^{m}$ Department of Anaesthesiology and Intensive Care Medicine, Havlickuv Brod Hospital, Havlickuv Brod, Czech Republic

${ }^{n}$ Department of Anaesthesiology and Intensive Care Medicine, Kosice-Saca Hospital, Kosice, Slovakia

${ }^{\circ}$ Department of Anaesthesiology and Intensive Care Medicine, Piestany Hospital, Piestany, Slovakia

${ }^{p}$ Department of Anaesthesiology and Intensive Care Medicine, Trencin Hospital, Trencin, Slovakia

Corresponding author: Petr Stourac, e-mail:petr.stourac@gmail.com 


\section{INTRODUCTION}

Obstetric general anaesthesia is a challenging area to study and its effects on maternal and neonatal outcomes must be considered. It is possible that an intervention could benefit one to the detriment of the other ${ }^{1}$. The classical technique of rapid sequence induction with predetermined doses of thiopentone and suxamethonium, cricoid pressure and avoidance of ventilation until tracheal intubation continues to evolve with the use of propofol and rocuronium now being more commonplace ${ }^{2-5}$. More recently, however, rocuronium has been associated with a lower Apgar score at one minute compared to suxamethonium, but no differences have been found between the two neuromuscular blockers in the Apgar scores at five and ten minutes or the umbilical arterial blood gases ${ }^{6}$.

In 2011, we performed a national study Obstetric Anaesthesia and Analgesia Month Attributes in the Czech Republic (OBAAMA-CZ), which demonstrated that use of general anaesthesia (GA) was common to facilitate caesarean section (CS). Subsequent to this, the Obstetric Anaesthesia and Analgesia Month Attributes International (OBAAMA-INT) survey was undertaken in the Czech Republic and Slovakia ${ }^{7,8}$. Its primary aim was to assess the practices and techniques in an obstetric anaesthesia care, in particular for labour analgesia and CS, in 2015 (ref. ${ }^{9}$ ). Due to an intensive educational activity in years 2011-2015 there was a significant increase in the rate of regional anaesthesia for CS (63\% vs. 53\%) ( ref. $\left.^{7,10}\right)$.

This article represents the secondary analysis of the OBAAMA-INT study and summarizes the impact of RA versus GA techniques in CS on the Apgar score in the Czech Republic and Slovakia.

\section{MATERIALS AND METHODS}

OBAAMA-INT was approved by the Ethics Committee for Multicenter Studies of the University Hospital Brno for the Czech Republic and by the Ethics Committee for Multicenter Studies of the University Hospital Kosice for Slovakia. It was decided that informed consent from the patients was not needed. The project, endorsed by the Czech Society of Anaesthesia and Intensive Care Medicine (CSARIM) and Slovak Society of Anaesthesiology and Intensive Medicine (SSAIM), was registered at https://clinicaltrials.gov (NCT02380586). All departments of anaesthesia that provided obstetric anaesthesia were personally contacted and requested to participate in the one-month study, which they could do so through an electronic application form available on the survey website (obaama.registry.cz).

The aim of this cross-sectional international survey was to describe the practice of obstetric anaesthesia, labour analgesia and anaesthesia for CS, in the Czech Republic and the Slovakia.

Data was entered through the use of a structured questionnaire authored by the OBAAMA-INT Steering Committee via an online database CLADE-IS, created by the Institute of Biostatistics and Analyses, Masaryk University (IBA, MU).

First, we retrospectively obtained demographic and summary data for all participating centers in 2014. Second, we prospectively recorded every case of obstetric anaesthesia (labour analgesia, anaesthesia for CS, early postpartum anaesthesia in 2 hours after delivery) at each institution over a one-month period in November 2015. Data obtained from 2014 were compared to data recorded in the reference month in 2014. Every record was related to an individual parturient and along with analgesia/anaesthesia data contained the following sections: demographic data, medical history, information on delivery (spontaneous or CS) and information on newborn (singleton or multiple birth, sex, weight, $\mathrm{pH}$ of arterial or venous cord blood, and Apgar score).

\section{Statistical Analysis}

The primary end point of our analysis was the neonatal outcome, which was evaluated using the Apgar scores at the 1, 5 and $10 \mathrm{~min}$ assessed by a certified neonatologist. The Apgar score was categorized as either less than seven or more than or equal to seven as the former has been associated with poorer neonatal outcomes at five minutes ${ }^{11}$.

We analyzed data of all first neonates, excluding the second neonates from multiple pregnancies. Furthermore, we analyzed neonates born via CS collectively and separately, after excluding those with fetal pathology (gestational age less than 37 weeks, birth weight less than 2500 $\mathrm{g}$, born in perinatological centers) and born by an acute CS to eliminate possible confounding factors. To examine the influence of GA on the Apgar scores, we analyzed the Apgar scores in two subgroups according to the emergency of procedure and the indication of GA; acute CS versus elective CS and time urgency as indication for CS in GA versus other indications for GA (parturient preference, neuraxial blockade failure, timing of low molecular weight heparin application, bleeding complications, placentation disorder and other). Finally, we evaluated only neonates from women who underwent CS with GA, who were intubated with rocuronium and suxamethonium.

Data analysis was carried out using statistical software SPSS 24 (IBM Corporation, Armonk, NY). Standard frequency tables and summary statistics were used to describe the baseline demographic and clinical characteristics. Categorical variables have been presented as number (\%). Continuous variables have been presented as mean (standard deviation) and median $\left(5^{\text {th }}\right.$ and $95^{\text {th }}$ percentile). The differences in the frequencies between the two groups of RA and GA were tested using the Fisher's exact test. The Mann-Whitney U test was used to assess differences in the continuous variables. All comparison tests were conducted at the $5 \%$ significance level.

\section{RESULTS}

Over the course of the survey period, 10119 births were registered in participating centers registered in 
Table 1. Demographics of all pregnant patients who delivered by caesarean section.

\begin{tabular}{|c|c|c|}
\hline & $\operatorname{CZE}(n=1689)$ & SVK $(n=859)$ \\
\hline \multicolumn{3}{|l|}{ ASA } \\
\hline 1 & $937(55.5)$ & $461(53.7)$ \\
\hline 2 & $664(39.3)$ & $362(42.1)$ \\
\hline 3 & $77(4.6)$ & $35(4.1)$ \\
\hline 4 & $5(0.3)$ & $0(0.0)$ \\
\hline 5 & $6(0.4)$ & $1(0.1)$ \\
\hline \multicolumn{3}{|l|}{ Gravidity } \\
\hline 1 & $789(46.7)$ & $425(49.5)$ \\
\hline 2 & $584(34.6)$ & $267(31.1)$ \\
\hline$>2$ & $316(18.7)$ & $167(19.4)$ \\
\hline Age (y) & $\mathrm{n}=1669 ; 31.6(22.3 ; 40.0) / 31.6(5.3)$ & $\mathrm{n}=846 ; 31.1(20.5 ; 39.8) / 30.9(5.8)$ \\
\hline$\leq 25$ & $188(11.1)$ & $139(16.2)$ \\
\hline $26-30$ & $442(26.2)$ & $219(25.5)$ \\
\hline $31-35$ & $571(33.8)$ & $267(31.1)$ \\
\hline $36-40$ & $386(22.9)$ & $182(21.2)$ \\
\hline$>40$ & $82(4.9)$ & $39(4.5)$ \\
\hline Gestational week & $\mathrm{n}=1687 ; 39.0(34.0 ; 41.0) / 38.6(2.3)$ & $\mathrm{n}=859 ; 39.0(34.0 ; 41.0) / 38.7(2.4)$ \\
\hline $24-36$ & $215(12.7)$ & $88(10.2)$ \\
\hline $37-40$ & 1214 (71.9) & $645(75.1)$ \\
\hline$>40$ & $258(15.3)$ & $126(14.7)$ \\
\hline Weight $(\mathrm{kg})$ & $\mathrm{n}=1689 ; 80.0(60.0 ; 113.0) / 82.1(16.3)$ & $\mathrm{n}=859 ; 76.0(58.0 ; 104.0) / 77.7(14.7)$ \\
\hline Height $(\mathrm{cm})$ & $\mathrm{n}=1597 ; 167.0(155.0 ; 178.0) / 166.5(7.1)$ & $\mathrm{n}=854 ; 165.0(155.0 ; 176.0) / 165.5(7.3)$ \\
\hline BMI & $\mathrm{n}=1597 ; 28.6(22.5 ; 39.7) / 29.6(5.5)$ & $\mathrm{n}=854 ; 27.6(21.6 ; 37.3) / 28.4(5.1)$ \\
\hline$<18.5$ & $5(0.3)$ & $2(0.2)$ \\
\hline $18.5-24.9$ & $285(16.9)$ & $223(26.0)$ \\
\hline $25.0-29.9$ & $667(39.5)$ & $365(42.5)$ \\
\hline $30.0-34.9$ & $410(24.3)$ & $188(21.9)$ \\
\hline$\geq 35.0$ & $230(13.6)$ & $76(8.8)$ \\
\hline \multicolumn{3}{|l|}{ History of pregnancy } \\
\hline PROM & $139(8.2)$ & $37(4.3)$ \\
\hline Gestational diabetes & $130(7.7)$ & $43(5.0)$ \\
\hline Gestational hypertension & $120(7.1)$ & $34(4.0)$ \\
\hline Coagulation disorders & $75(4.4)$ & $44(5.1)$ \\
\hline Preeclampsia & $84(5.0)$ & $54(6.3)$ \\
\hline Thrombocytopenia & $15(0.9)$ & $15(1.7)$ \\
\hline HELLP & $11(0.7)$ & $2(0.2)$ \\
\hline Eclampsia & $0(0.0)$ & $1(0.1)$ \\
\hline \multicolumn{3}{|l|}{ Neurologic disorders } \\
\hline Epilepsy & $16(0.9)$ & $9(1.0)$ \\
\hline Disorders of spine and spinal injuries & $16(0.9)$ & $8(0.9)$ \\
\hline Multiple sclerosis & $2(0.1)$ & $2(0.2)$ \\
\hline Myastenia gravis & $1(0.1)$ & $1(0.1)$ \\
\hline Other & $26(1.5)$ & $12(1.4)$ \\
\hline \multicolumn{3}{|l|}{ Placetal disorders } \\
\hline Placental abruption & $22(1.3)$ & $11(1.3)$ \\
\hline Praevia & $26(1.5)$ & $6(0.7)$ \\
\hline Placental insufficiency & $19(1.1)$ & $7(0.8)$ \\
\hline Placenta accreta/increta/percreta & $2(0.1)$ & $2(0.2)$ \\
\hline
\end{tabular}

Data are presented as $\mathrm{n}(\%)$, mean $( \pm \mathrm{SD})$ or median $\left(5^{\text {th}} ; 95^{\text {th }}\right.$ percentile). ASA: American Society of Anesthesiologists. BMI: Body Mass Index. CZE: Czech Republic study group. HELLP: Haemolysis, Elevated Liver enzymes and Low Platelets. PROM: premature rupture of membranes. SVK: Slovak study group. 
Table 2. Short term neonatal outcomes of neonates delivered by caesarean section.

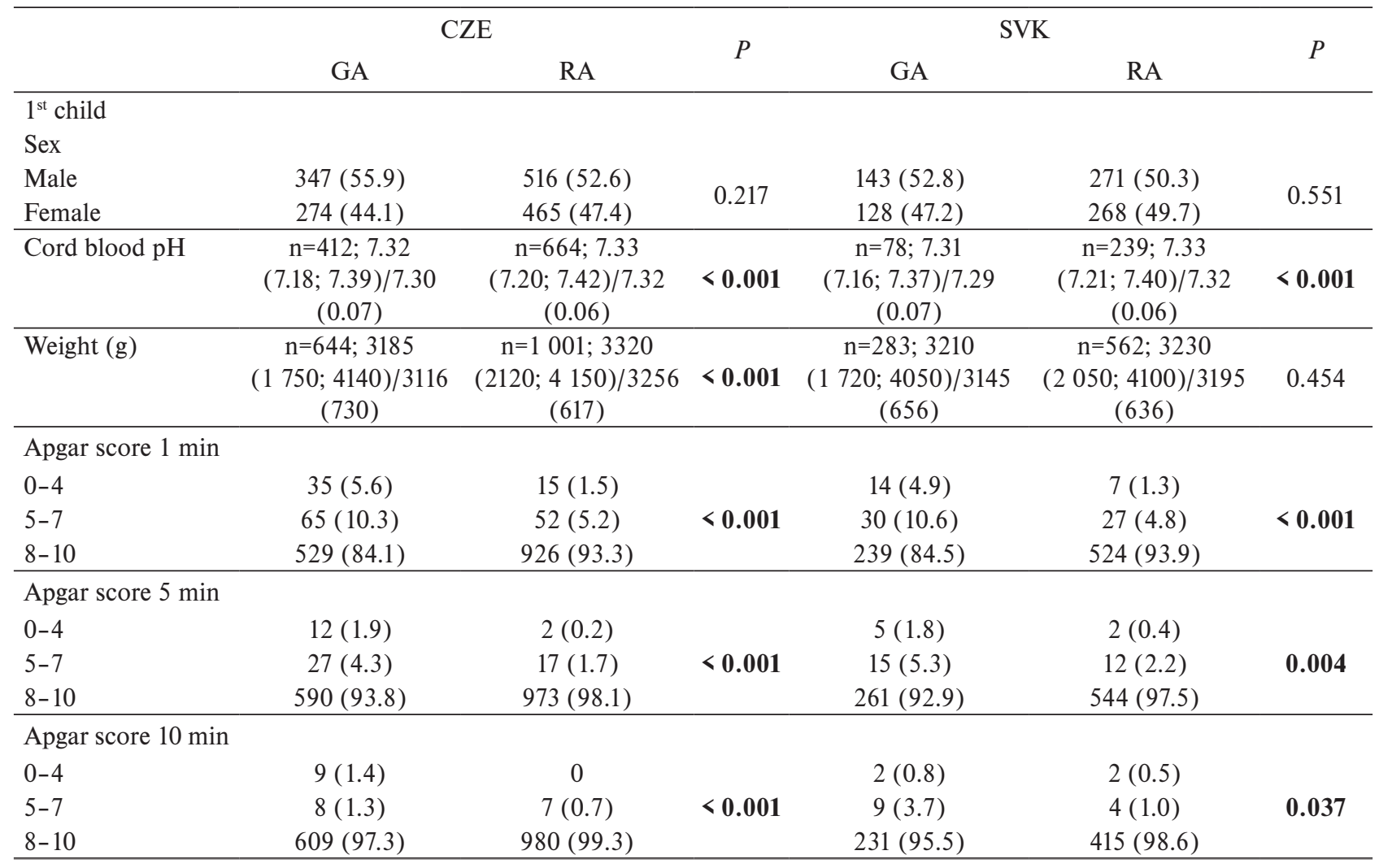

Data are presented as $\mathrm{n}(\%)$, mean $( \pm \mathrm{SD})$ or median $\left(5-95^{\text {th }}\right.$ percentile). CZE: Czech Republic study group. SVK: Slovak study group.

Table 3. Evaluation of effect of mode of anaesthesia on Apgar score of newborns delivered by caesarean section; all first newborns and selected first newborns (weighing more than $2500 \mathrm{~g}$, delivered at term by elective caeserean section only in a non-perinatological center).

\begin{tabular}{|c|c|c|c|}
\hline All first newborns & General anaesthesia & Regional anaesthesia & $P$ \\
\hline \multicolumn{4}{|l|}{ Apgar score $1 \mathrm{~min}$} \\
\hline $0-6$ & $93(10.2 \%)$ & $61(3.9 \%)$ & $<0.001$ \\
\hline $7-10$ & $819(89.8 \%)$ & $1490(96.1 \%)$ & \\
\hline \multicolumn{4}{|l|}{ Apgar score $5 \mathrm{~min}$} \\
\hline $0-6$ & $36(4.0 \%)$ & $12(0.8 \%)$ & $<0.001$ \\
\hline $7-10$ & $874(96.0 \%)$ & $1538(99.2 \%)$ & \\
\hline \multicolumn{4}{|l|}{ Apgar score $10 \mathrm{~min}$} \\
\hline $0-6$ & $15(1.7 \%)$ & $8(0.6 \%)$ & 0.009 \\
\hline $7-10$ & $853(98.3 \%)$ & $1400(99.4 \%)$ & \\
\hline Selected first newborns & General anaesthesia & Regional anaesthesia & $P$ \\
\hline \multicolumn{4}{|l|}{ Apgar score $1 \mathrm{~min}$} \\
\hline $0-6$ & $1(0.9 \%)$ & $10(1.9 \%)$ & 0.699 \\
\hline $7-10$ & $108(99.1 \%)$ & $505(98.1 \%)$ & \\
\hline \multicolumn{4}{|l|}{ Apgar score $5 \mathrm{~min}$} \\
\hline $0-6$ & $0(0.0 \%)$ & $1(0.2 \%)$ & 0.999 \\
\hline $7-10$ & $108(100.0 \%)$ & $514(99.8 \%)$ & \\
\hline \multicolumn{4}{|l|}{ Apgar score $10 \mathrm{~min}$} \\
\hline $0-6$ & $0(0.0 \%)$ & $1(0.2 \%)$ & 0.999 \\
\hline $7-10$ & $107(100.0 \%)$ & $467(99.8 \%)$ & \\
\hline
\end{tabular}

Data are presented as number (\%). 
Table 4. Differences in Apgar score in neonates delivered by elective or emergency caesarean section under general anaesthesia.

\begin{tabular}{|c|c|c|c|}
\hline & Elective CS $(n=267)$ & Acute CS $(n=689)$ & $P$ \\
\hline \multicolumn{4}{|c|}{ Apgar score $1 \mathrm{~min}$} \\
\hline $0-6$ & $7(2.8 \%)$ & $86(13.0 \%)$ & $<0.001$ \\
\hline $7-10$ & $245(97.2 \%)$ & $574(87.0 \%)$ & \\
\hline \multicolumn{4}{|c|}{ Apgar score $5 \mathrm{~min}$} \\
\hline $0-6$ & $4(1.6 \%)$ & $32(4.9 \%)$ & 0.022 \\
\hline $7-10$ & $247(98.4 \%)$ & $627(95.1 \%)$ & \\
\hline \multicolumn{4}{|c|}{ Apgar score $10 \mathrm{~min}$} \\
\hline $0-6$ & $1(0.4 \%)$ & $14(2.2 \%)$ & 0.081 \\
\hline \multirow[t]{2}{*}{$7-10$} & $239(99.6 \%)$ & $614(97.8 \%)$ & \\
\hline & Urgent indication for GA $(n=497)$ & Other indications for $\mathrm{GA}^{*}(\mathrm{n}=459)$ & $P$ \\
\hline \multicolumn{4}{|c|}{ Apgar score $1 \mathrm{~min}$} \\
\hline $0-6$ & $67(14.1 \%)$ & $26(6.0 \%)$ & $<0.001$ \\
\hline $7-10$ & $409(85.9 \%)$ & $410(94.0 \%)$ & \\
\hline \multicolumn{4}{|c|}{ Apgar score $5 \mathrm{~min}$} \\
\hline $0-6$ & $26(5.5 \%)$ & $10(2.3 \%)$ & 0.016 \\
\hline $7-10$ & $448(94.5 \%)$ & $426(97.7 \%)$ & \\
\hline \multicolumn{4}{|c|}{ Apgar score $10 \mathrm{~min}$} \\
\hline $0-6$ & $13(2.9 \%)$ & $2(0.5 \%)$ & 0.007 \\
\hline $7-10$ & $436(97.1 \%)$ & $417(99.5 \%)$ & \\
\hline
\end{tabular}

* Parturient preference $(n=250)$; Neuraxial blockade failure $(n=70)$; LMWH application $(n=22)$; Bleeding complications $(n=20)$; Placentation disorder $(\mathrm{n}=13)$; Other $(\mathrm{n}=84)$

the OBAAMA-INT database; 7259 in the Czech study group (CZE), 2863 in the Slovak study group (SVK). In November 2015 , they represented $80.4 \%$ of all deliveries in the Czech and the Slovak Republics, where there were 12586 in total and 8275 and 4311, respectively.

All departments of anaesthesia that provide obstetric anaesthesia were personally contacted (15 university hospitals, 13 regional, 121 local) with a request to participate in the one-month study that monitored anaesthetic practices, delivered by anaesthesiologists, in the peripartum period. The response rate was $71 \%$ ( 70 of 95 departments in the Czech Republic, 35 of 54 centers in the Slovakia); participating centers represented $87.7 \%$ of all births in the Czech Republic and $66.4 \%$ of all births in the Slovakia during the study period. In total, data of 3590 parturients who received anaesthesia/analgesia for labour were collected; there were 107 cases of twins, 105 (98\%) of them were delivered via CS (71 in CZE, 34 in SVK). There were no statistically significant differences in demographic characteristics of parturients who delivered by CS between the CZE and the SVK (Table 1).

In Table 2 you can see statistically significant differences in Apgar scores in groups of GA and RA for CS in both national surveys. This significant difference is reported only in the group of first born children, but not in the group of second born children. Therefore the further analysis of neonatal outcomes was performed with the subgroup of firstborns.

Compared to GA, the use of RA for CS was associated with statistically significant increases in the Apgar scores at 1, 5 and $10 \mathrm{~min}$. Further analysis of Apgar scores shows different results when the newborns with fetal pathology were excluded from analysis. There was no statistically significant difference between the two groups of RA and GA (Table 3).

The next section of the analysis was concerned with the GA effect on the Apgar score. Compared to elective $\mathrm{CS}$, acute $\mathrm{CS}$ was associated with decreases in the Apgar score at 1 and $5 \mathrm{~min}$ but not $10 \mathrm{~min}$. General anaesthesia which was performed for time urgency indication $(n=497)$ was related to lower Apgar scores at 1, 5 and 10 min relative to those undertaken for non-urgent indications; maternal preference $(n=250)$, placentation disorderds $(n=13)$, timing of low molecular weight heparin administration $(n=22)$, neuraxial blockade failure $(n=70)$ and haemorrhage complications $(n=20)$ and others $(n=84)$ (Table 4$)$.

In the final part of the analysis of GA subgroup, we draw our attention to the impact of neuromuscular blocking agent choice for intubation on the Apgar score in newborn. Of all 956 patients who received GA for CS, 889 and 21 were intubated with suxamethonium and rocuronium, respectively, and no statistically significant differences in Apgar scores were found.

\section{DISCUSSION}

We present the results of an international survey that was designed to identify obstetric anaesthesia practices in the Czech Republic and Slovakia. Due to the high rate of involvement of obstetric centers and collection of data on $87.7 \%$ of all deliveries in the Czech Republic and $66.4 \%$ of all births in Slovakia during one month study period, the results are quite representative ${ }^{9}$.

To determine neonatal outcomes we used the Apgar score because it is a standardized, accepted method of 
reporting the status of the newborn immediately after birth and at subsequent time points and the response to resuscitation, if required ${ }^{12}$. Recording the Apgar score by experienced neonatologist in every newborn is part of good clinical practice in participating hospitals. An interindividual variability in Apgar scores recorded by different neonatologists was expect to be low, because Bashambu et al. shown almost perfect agreement in Apgar scores 1 and 5 min in full term infants ${ }^{13}$. We set the cut-off value as an Apgar score 7, because neonatal complications including respiratory distress, feeding problems, hypothermia, and seizures are all significantly associated with the Apgar score lower than 7 (ref. ${ }^{11,14}$ ).

We recorded significant difference in Apgar scores of the 1,5 and $10 \mathrm{~min}$ in groups of GA and RA, preferring RA. This difference was present in data from the Czech Republic as well as from Slovakia. The above-mentioned difference was not present in Apgar scores of second babies from multiple pregnancies. Therefore, for further analysis we used only data of singleton pregnancies and first babies from multiple pregnancies.

Our finding of preferable neonatal outcomes in group of RA for CS is consistent with other studies maintaining that neonatal outcome is better with RA than with GA (ref. ${ }^{15,16}$ ). On the other hand, there are some studies showing no difference in neonatal outcome between the two groups ${ }^{17,18}$. Most studies that report no difference are those done on women who had elective operations ${ }^{19}$ while those done on emergencies tend to report a positive difference in neonatal outcome with RA compared with GA $\left(\right.$ ref. $\left.^{20,21}\right)$.

After elimination of possible confounding factors (acute CS, preterm infant, low birth weight, born in perinatological center), we analyzed Apgar scores of only healthy full term infants and found no significant difference between RA and GA in any of the 1, 5 and 10-min intervals. This suggested that the main role in worse neonatal outcome in GA group is played by time urgency. To verify this, we analyzed this subgroup of infants born by CS under GA. We found significantly worse 1-min and 5-min Apgar scores in group of acute CS compared to a planned CS. The same trend of significantly worse Apgar scores (the 1, 5 and $10 \mathrm{~min}$ ) was also present in comparison of $\mathrm{CS}$ with indication for GA recorded as time urgency and CS in GA with other indication. This finding supports the evidence from previous studies that neither GA nor RA is superior to the other in terms of neonatal outcomes ${ }^{22}$.

In our survey we failed to record a difference in Apgar scores of newborns whose mothers were intubated for CS in rocuronium compared to mothers intubated in suxamethonium, recently shown in prospective analysis of 525 newborns ${ }^{6}$. However, our analysis of neonatal outcomes in the subgroup defined by women undergoing CS with rocuronium for intubation is underpowered because of the limited sample size; therefore the results should be interpreted with caution.

There are many factors that alter the effects of neuromuscular blocking drugs in the pediatric age group ${ }^{23}$. The maturation of neuromuscular transmission is multi- factorial and this process depends more on the duration of extra-uterine life than on postconceptional age ${ }^{24}$. It is completed in the age of approximately 2 months $^{25}$. Also the maturation of elimination pathways can explain the different age-dependent duration of the effect of various NMBA, the total plasma clearance of rocuronium in infants is $40 \%$ less than children ${ }^{26}$. Since the first study to describe effects of the rocuronium use in obstetric anaesthesia was held in 1994 ( ref. $^{27}$ ), there are no data on the placental transfer of rocuronium after doses greater than $0.6 \mathrm{mg} / \mathrm{kg}\left(\right.$ ref. $^{1,28}$ ).

The limitations of our study are the duration of the study period, the number of patients included and missing data of some newborns. Main strengths of the study are the prospective design and the inclusion of all parturients of each center in the study (all consecutive) ${ }^{9}$.

\section{CONCLUSION}

In conclusion, this secondary analysis of prospective international survey represents important data on current anaesthesiologist's practices for CS and its impact on the Apgar score in the Czech Republic and Slovakia.

Acknowledgement: The authors thank all the members of OBAAMA-INT Study Group and all other investigators from participating centers for their extraordinary work on these national surveys. The members of OBAAMA-INT Study Group are: Vladimir Zemanek (Boskovice, CZE), Vladimir Hluchy (Breclav, CZE), Eliska Hamrikova, Hana Harazim, Ondrej Hruza, Jiri Jarkovsky, Martina Kosinova, Jiri Libra, Lucia Mackova, Hana Robotkova, Daniel Schwarz, Dagmar Seidlova, Olga Smekalova, Petr Stourac, Michal Svoboda, Katerina Vajcnerova, Hana Zelinkova (Brno, CZE), Jan Cepak (Ceske Budejovice, CZE), Jan Nemec (Chomutov, CZE), Martin Zemanek (Chrudim, CZE), Nikola Benesova (Decin, CZE), Vladislav Cerny (Domazlice, CZE), Robert Bocek (Havirov, CZE), Jitka Mannova (Havlickuv Brod, CZE), Jiri Steinbach (Horovice, CZE), Xenia Silova (Hradec Kralove, CZE), Petr Kudrna (Jesenik, CZE), Petr Horacek, Bohdan Trnka (Jihlava, CZE), Gabriela Pohorala (Jilemnice, CZE), Ladislav Rychtarik (Jindrichuv Hradec, CZE), Zdenek Kos (Karlovy Vary, CZE), Radmila Vojkuvkova (Karvina, CZE), Kamil Kodras (Kladno, CZE), Miriam Gredova (Klatovy, CZE), Jiri Blazek (Kolin, CZE), Slavka Stajancova (Krnov, CZE), Elena Kratka (Kyjov, CZE), Alena Podlipna (Liberec, CZE), Ludmila Kesslerova (Litomerice, CZE), Petra Preisova (Melnik, CZE), Pavel Kettner (Mlada Boleslav, CZE), Martin Segovia (Most, CZE), Petr Stepanek (Nachod, CZE), Marek Pospisil (Neratovice, CZE), Petr Kozar (Nove Mesto na Morave, CZE), Petr Uhlig (Novy Jicin, CZE), Martina Kirchnerova, Zdenek Mrozek (Olomouc, CZE), Bozena Jezova (Opava, CZE), Hana Durdova, Christian Kufa, Blazena Zaoralova, (Ostrava, CZE), Jana Sutakova (Ostrov, CZE), Frantisek Barta (Pelhrimov, CZE), Tomas Piksa (Pisek, CZE), Roman Bosman, Roman Svitak (Plzen, CZE), Petr Ruzicka (Prachatice, CZE), Jan Blaha, 
Radka Klozova, Marketa Kopecka, Zdenka Krupkova, Pavlina Noskova, Jiri Roskot, Jaroslava Scamburova, Valter Zenkner (Praha, CZE), Petr Dusek (Prerov, CZE), Jana Popieluchova (Pribram, CZE), Greta Smesna (Prostejov, CZE), Pavel Padrta (Rakovnik, CZE), Pavel Fiala (Roudnice nad Labem, CZE), Jan Belic (Rumburk, CZE), Ales Vlcek (Rychnov nad Kneznou, CZE), Jiri Dvorak (Slany, CZE), Alexandr Abosi (Sokolov, CZE), Vladislav Kriz (Stod, CZE), Marek Zboril (Strakonice, CZE), Radovan Prchlik (Tabor, CZE), Barbora Nemcova (Teplice, CZE), Simona Hnatova (Trebic, CZE), Irena Snajdrova (Uherske Hradiste, CZE), Pavel Neumann (Usti nad Labem, CZE), Michal Zapletal (Usti nad Orlici, CZE), Marie Vopelkova (Vyskov, CZE), Lubomir Vecera (Zlin, CZE), Iva Sprinclova (Znojmo, CZE), Juraj Kusy (Banovce, SK), Diana Valcuhova (Banska Bystrica, SK), Maria Sramkova (Bojnice, SK), Viera Lesna, Jaroslava Mackova, Renata Tobolakova, Lucia Varosova (Bratislava, SK), Frantisek Mican (Dolny Kubin, SK), Sergej Susko (Humenne, SK), Serhiy Rak (Kezmarok, SK), Jozef Firment, Monika Grochová, Gabriela Mizlova, Jana Simonova, Jan Slavik, Marcela Slukova (Kosice, SK), Zuzana Baluchova (Krompachy, SK), David Druska (Liptovsky Mikulas, SK), Stanislava Richterova (Martin, SK), Lucia Holukova, Marta Tkacova (Michalovce, SK), Peter Mokos (Myjava, SK), Alzbeta Magyarova (Nitra, SK), Zuzana Novakova (Piestany, SK), Ivana Berezna, Ivana Vysokaiova (Poprad, SK), Luba Jurcikova (Povazska Bystrica, SK), Hedviga Ivankova (Presov, SK), Garri Slovodianiuk (Revuca, SK), Sharifullah Azizi (Rimavska Sobota, SK), Ivana Ivanova (Roznava, SK), Marian Paulik (Ruzomberok, SK), Ivo Horsky (Skalica, SK), Andrea Hennelova (Snina, SK), Lubos Filiac (Stara Lubovna, SK), Andrea Zavodova (Svidnik, SK), Zuzana Drgonova (Topolcany, SK), Jarmila Janikova (Trebisov, SK), Lubica Misakova (Trencin, SK), Bozena Horanova (Trstena, SK), Lucia Tesakova (Vranov nad Toplou, SK).

This work was supported by the research grant of the Czech Society of Anaesthesiology and Intensive Care Medicine - project no. CSARIM201501.

The preliminary results of this study were presented as abstracts and posters at the Euroanaesthesia 2016, London, UK and Euroanaesthesia 2017, Geneva, Switzerland.

Author contributions: $\mathrm{HH}, \mathrm{PS}, \mathrm{JB}, \mathrm{MG}, \mathrm{RK}, \mathrm{PN}, \mathrm{DS}, \mathrm{SR}$, XS, BJ, JSt, MZ, JM, JS1, ZN, LM, JF: manuscript writing and literature search, data collection and interpretation, study design; MS, JJ: data collection and analysis, manuscript writing.

Conflict of interest statement: The authors state that there are no conflicts of interest regarding the publication of this article.

\section{REFERENCES}

1. Rucklidge M. Paralysis analysis - does choice of muscle relaxant for obstetric general anaesthesia influence neonatal outcomes? Int J Obstet Anesth 2017;32:1-3.

2. Lucas DN, Yentis SM. Unsettled weather and the end for thiopental?
Obstetric general anaesthesia after the NAP5 and MBRRACE-UK reports. Anaesthesia 2015;70(4):375-9.

3. Devroe S, Van de Velde M, Rex S. General anesthesia for caesarean section. Curr Opin Anaesthesiol 2015;28(3):240-6.

4. Mushambi MC, Kinsella SM, Popat M, Swales H, Ramaswamy KK, Winton AL, Quinn AC, Obstetric Anaesthetists' Association, Difficult Airway Society. Obstetric Anaesthetists' Association and Difficult Airway Society guidelines for the management of difficult and failed tracheal intubation in obstetrics. Anaesthesia 2015;70(11):12861306.

5. Desai N, Wicker J, Sajayan A, Mendonca C. A survey of practice of rapid sequence induction for caesarean section in England. Int J Obstet Anesth 2018;36:3-10.

6. Kosinova M, Stourac P, Adamus M, Seidlova D, Pavlik T, Janku P, Krikava I, Mrozek Z, Prochazka M, Klucka J, Stoudek R, Bartikova I, Harazim H, Robotkova H, Hejduk K, Hodicka Z, Kirchnerova M, Francakova J, Pyszkova LO, Hlozkova J, Sevcik P. Rocuronium versus suxamethonium for rapid sequence induction of general anaesthesia for caesarean section: influence on neonatal outcomes. Int J Obstet Anesth 2017;32:4-10.

7. Stourac P, Blaha J, Noskova P, Klozová R, Seidlová D, Jarkovský J, Zelinková H, Skupina OC. Analgesia for labour in the Czech Republic in the year 2011 from the perspective of OBAAMA-CZ study - prospective national survey. Ceska Gynekol 2015;80(2):127-34. (In Czech)

8. Stourac P, Blaha J, Klozova R, Noskova P, Seidlova D, Brozova L, Jarkovsky J. Anesthesia for Cesarean Delivery in the Czech Republic: A 2011 National Survey. Anesth Analg 2015;120(6):1303-8.

9. Bláha J, Štourač $P$, Grochová $M$, Klozová R, Richterová S, Nosková P, Seidlová D, Zenkner V, Novotný A, Schwarz D, Ščamburová J, Kosinová M, Kufa C, Kirchnerová M, Macková J, Várošová L, Toboláková R, Cepák J, Firment J; OBAAMA-INT Study Group. Labor analgesia in Czech Republic and Slovakia: a 2015 national survey. Int J Obstet Anesth 2018;35:42-51.

10. Stourac P, Blaha J, Grochova M, Firment J, Noskova P, Schwarz D. Preferred techniques for obstetric anaesthesia and analgesia in Czech and Slovak Republic in the year 2015 - prospective observational survey. Eur J Anaesthesiol 2016;33:182-2.

11. Sabol BA, Caughey AB. Acidemia in neonates with a 5-minute Apgar score of 7 or greater - What are the outcomes? Am J Obstet Gynecol 2016;215(4):6.

12. Committee Opinion No. 644: The Apgar Score. Obstet Gynecol 2015;126(4):52-5

13. Bashambu MT, Whitehead H, Hibbs AM, Martin RJ, Bhola M. Evaluation of Interobserver Agreement of Apgar Scoring in Preterm Infants. Pediatrics 2012;130(4):982-7.

14. Thavarajah $\mathrm{H}$, Flatley $\mathrm{C}$, Kumar $\mathrm{S}$. The relationship between the five minute Apgar score, mode of birth and neonatal outcomes. J Matern Fetal Neonatal Med 2018;31(10):1335-41.

15. Abboud TK, Nagappala S, Murakawa K, David S, Haroutunian S, Zakarian M, Yanagi T, Sheikh-Ol-Eslam A. Comparison of the effects of general and regional anesthesia for cesarean section on neonatal neurologic and adaptive capacity scores. Anesth Analg 1985;64(10):996-1000.

16. Ong BY, Cohen MM, Palahniuk RJ. Anesthesia for Cesarean Section Effects on Neonates. Anesth Analg 1989;68(3):270-5.

17. Fox GS, Smith JB, Namba Y, Johnson RC. Anesthesia for Cesarean Section - further studies. Am J Obstet Gynecol 1979;133(1):15-9.

18. Zagorzycki MT, Brinkman CR. The effect of general and epidural anesthesia upon neonatal Apgar scores in repeat cesarean section. Surg Gynecol Obstet 1982;155(5):641-5.

19. Korkmaz F, Eksioglu B, Hanci A, Basgul A. Comparison of combined spinal epidural block and general anesthesia for cesarean section. Reg Anesth Pain Med 2004;29(77).

20. Dyer RA, Els I, Farbas J, Torr GJ, Schoeman LK, James MF. Prospective, randomized trial comparing general with spinal anesthesia for cesarean delivery in preeclamptic patients with a nonreassuring fetal heart trace. Anesthesiology. 2003;99(3):561-9.

21. Palmer $E$, Ciechanowicz $S$, Reeve $A$, Harris $S$, Wong DJN, Sultan $P$. Operating room-to-incision interval and neonatal outcome in emergency caesarean section: a retrospective 5-year cohort study. Anaesthesia 2018;73(7):825-31.

22. Afolabi BB, Lesi FEA. Regional versus general anaesthesia for caesarean section. Cochrane Database Syst Rev 2012(10):89. 
23. Carlos R, Nani F, Donald de Boer H. Re: Influence on neonatal outcomes of rocuronium for rapid sequence induction of general anaesthesia for caesarean section. Rev Bras Anestesiol 2017;67(5):552-3.

24. Meretoja $\mathrm{O}, \mathrm{Kokki} \mathrm{H}$. Neuromuscular blocking agents in children. In Bissonnette B, editors. Pediatric Anesthesia: Basic Principles - State of the Art - Future. Shelton, Connecticut, USA: People's Medical Publishing House; 2011. p. 416-440.

25. Goudsouzian NG, Standaert FG. The Infant and the Myoneural Junction. Anesth Analg 1986;65(11):1208-17.
26. Wierda J, Meretoja OA, Taivainen T, Proost JH. Pharmacokinetics and pharmacokinetic-dynamic modelling of rocuronium in infants and children. Br J Anaesth 1997;78(6):690-5.

27. Abouleish E, Abboud T, Lechevalier T, Zhu J, Chalian A, Alford K. Rocuronium (ORG-9426) for Cesarean Section. Br J Anaesth 1994;73(3):336-41.

28. Guay J, Grenier Y, Varin F. Clinical pharmacokinetics of neuromuscular relaxants in pregnancy. Clin Pharmacokinet 1998;34(6):483-96. 